\title{
Should Monetary Policy Respond to Asset Price Bubbles? Some EXPERIMENTAL Results
}

\author{
Andrew J. Filardo \\ JULY 2001 \\ RWP 01-04
}

Research Division

Federal Reserve Bank of Kansas City

Andrew J. Filardo is an assistant vice president and economist at the Federal Reserve Bank of Kansas City. The author would like to thank V.V. Chari, Craig Hakkio, Harvey Rosenblum, Eric Rosengren, seminar participants at the Federal Reserve Bank of Kansas City, and participants in the session on Asset Price Bubbles at the 2001 Western Economic Association conference for helpful comments, and Hank Hui for valuable research assistance. The views expressed in this paper are those of the author and do not necessarily represent the views of the Federal Reserve Bank of Kansas City or the Federal Reserve System.

Filardo email: andrew.j.filardo@kc.frb.org 


\begin{abstract}
Should central banks respond to asset price bubbles? This paper explores this monetary policy question in a hypothetical economy subject to asset price bubbles. Despite the highly stylized structure of the model, the results reveal several practical monetary policy lessons. First, a monetary authority should generally respond to asset prices as long as asset prices contain reliable information about inflation and output. Second, this finding holds even if a monetary authority cannot distinguish between fundamental and bubble asset price behavior. Third, a monetary authority's desire to respond to asset prices falls dramatically as its preference to smooth interest rates rises. Finally, a monetary authority should not respond to asset prices if there is considerable uncertainty about the macroeconomic role of asset prices.
\end{abstract}

J.E.L. classification: E5, G1

Keywords: Monetary policy, asset prices 


\section{INTRODUCTION}

In the last two decades, countries around the world have seen significant and persistent movements in asset prices. One important issue for central banks is whether the monetary authority should respond to asset prices to stabilize output and inflation variability. Conventional wisdom suggests that soaring asset prices and their collapse--behavior often thought of as the telltale signs of an asset price bubble--should have important consequences for output and inflation. When asset prices soar, consumers increase their consumption because wealth rises, and businesses increase investment because the cost of capital falls. In addition, this increase in aggregate demand is supposed to put upward pressure on inflation. In such an environment, a monetary authority interested in keeping inflation stable would generally have to tighten policy as asset prices rise and ease as asset prices fall.

While theoretically sound, the empirical correlations between asset price inflation and consumer price inflation are at odds with this conventional wisdom. In countries that experienced broad swings in asset prices, asset price inflation has tended to be correlated with stable or declining consumer price inflation. In fact, consumer price inflation often rises after asset prices collapse. This unconventional behavior has prompted controversy about how central banks should respond to asset prices to improve economic outcomes, possibly suggesting that central banks should ease rates as asset prices rise and raise rates as asset prices collapse. ${ }^{1}$

Recent research on asset prices and monetary policy has provided no clear guidance on this issue because there is yet little consensus on how central banks should respond to asset prices, especially when there is the possibility of an asset price bubble. Moreover, progress has

\footnotetext{
${ }^{1}$ Central banks may also be interested in responding to stock market and housing market prices in order to reduce financial market volatility. It is not uncommon for large swings in asset prices--often linked to asset price bubbles-to be associated with periods of financial market turbulence. While responding to asset prices as they rise and as they fall may help mute financial fluctuations, the central bank may create moral hazard problems. This is an interesting issue but goes well beyond the scope of this paper.
} 
been limited in answering several fundamental policy questions about the role of asset prices in monetary policy. These questions include: (1) How are asset prices related to the economy? How can we interpret asset price movements? (3) And, should policymakers respond to asset price movements?

Several recent studies made some progress on answering this last question. Gertler and Bernanke $(1999,2001)$ examine an economy subject to asset price bubbles with a monetary authority that pursues a flexible inflation targeting policy. Asset prices in their macroeconomic model affect aggregate demand in three ways. Increasing asset prices boost consumption via a wealth effect, increase investment via a cost of capital effect, and raise net worth that stimulates aggregate demand via a financial accelerator channel. They find "to a first approximation, once the predictive content of asset prices for inflation has been accounted for, there should be no additional response of monetary policy to asset price fluctuations.”

Cecchetti et al., using the same model, somewhat surprisingly draw the opposite conclusion. They argue that a monetary authority can improve economic conditions by responding to asset price bubbles. One of their reasons for the difference in the results is that they explore a larger family of policy reaction functions. One drawback of their study, however, is that they restrict their analysis to deterministic asset price bubbles. Bernanke and Gertler (2001) argue that if Cecchetti et al. had accounted for stochastic asset price bubbles, they would have found no useful role for asset prices beyond what is reflected in expectations for future inflation.

Filardo (2000) studies the role of asset prices (but not asset price bubbles) in monetary policy in a different model than these other works. In that paper, I use a much simpler reducedform macroeconomic model that has been successfully used in other monetary policy research. My paper concludes that in a model without uncertainty about the role of asset prices in 
determining output and inflation, a monetary authority generally benefits from responding to asset prices. However, a monetary authority will not expect to benefit from responding to asset prices if it is sufficiently unsure about the macroeconomic consequences of asset prices.

To further explore this question of whether monetary policy should respond to asset prices, this paper extends the model of Filardo (2000) to include asset price bubbles and investigates the characteristics of optimal monetary policy. The next section of the paper lays out the model economy in which a random asset price bubble affects inflation and output. In such an environment, the monetary authority has the option to respond to overall asset price movements as well as to its fundamental and bubble components. The third section reports the results from various simulations and takes away several practical implications for monetary policy. The final section draws some conclusions and offers some suggestions for future research.

\section{MONETARY POLICY MODEL INCORPORATING ASSET PRICE BUBBLES}

This section builds on the small-scale monetary policy model of Rudebusch and Svensson by adding a role for asset price inflation--both the fundamental component and the bubble component. The model comprises three modeling blocks: the macroeconomic block, the asset price inflation block, and the monetary policy block. The Technical Appendix provides a concise mathematical summary of the model as well as the simulation methods used to produce the results.

\section{Macroeconomic Model Block}

The output and inflation block of the model is a standard $I S-P C$ model that includes roles for asset price inflation and asset price bubbles. In particular, output and inflation are specified as follows: 


\section{Output and Inflation Block}

$$
\begin{aligned}
& \text { (IS ) } y_{t}=-0.2 r_{t-1}+0.6 y_{t-1}+0.2\left(\pi_{A P, t-1}-\pi_{t-1}\right)+\varepsilon_{t} \\
& \text { (PC) } \pi_{t}=\pi_{t-1}+0.15 y_{t-1}-0.1 \pi_{B, t-1}+\eta_{t}
\end{aligned}
$$

The first equation is a standard dynamic $I S$-type equation linking real output growth, $y$, to the lagged real interest rate $\left(r_{t-1}\right)$, lagged real output growth $\left(y_{t-1}\right)$, lagged real asset prices $\left(\pi_{A P, t-1^{-}}\right.$ $\left.\pi_{t}\right)$, and an unpredictable demand shifter $\left(\varepsilon_{t}\right)$ representing changes in consumer and business confidence. $\pi_{A P, t-1}$ is overall asset price inflation and $\pi_{t}$ is consumer price inflation. Asset prices can be thought of as affecting output growth in several ways. For example, an increase in asset prices - either from fundamental or bubble components or both — can be thought of as increasing consumption spending via the wealth effect, increasing investment spending via the cost of capital effect, and increasing government spending via the political economy effect of greater tax revenues. This specification reflects the conventional view that asset price inflation boosts aggregate demand. ${ }^{2}$ The error term is assumed to be normally distributed with a zero mean and a $\sigma_{\varepsilon}^{2}(=1.2)$ variance.

The second equation is an accelerationist version of the Phillips curve that has been augmented to include the influence of a nominal asset price bubble $\left(\pi_{B, t-1}\right)$. The real output term captures the conventional wisdom that inflation tends to rise when the economy is operating above its potential and tends to slow when the economy is operating below potential. The output term also can be thought of as summarizing the various factors that affect resource utilization rates. The error term is assumed to be normally distributed with a zero mean and a $\sigma_{\eta}^{2}(=0.04)$ variance.

\footnotetext{
${ }^{2}$ The calibration was based on reasonable estimates from the literature rather than on econometric estimates. This approach can be justified by the near impossibility of estimating the bubble component of asset prices (Cogley). Moreover, the monetary policy lessons learned are fairly robust to a wide range of specifications.
} 
The role of asset prices in this $P C$ equation is novel. The presence of the asset price bubble reflects an empirical regularity rather than some theoretical justification. In many countries that saw a rapid runup in asset prices, consumer price inflation often remained well contained. For example, in Japan and the U.K. during the late 1980s or in the U.S. during the late 1990s, equity and real estate prices rose while inflation was quite stable. I read this empirical behavior to suggest that asset price bubbles may have the potential of reducing the user costs of capital sufficiently to hold unit labor costs and hence inflation low and stable.

Alternatively, asset price bubbles may spur potential output growth enough to offset price pressures of higher actual output. Whatever the theoretical justification, this $P C$ specification with an asset price bubble raises some interesting monetary policy issues that are not implied by conventional specifications. For example, if soaring asset prices lowers inflationary pressures, a monetary authority interested in keeping inflation stable may not want to follow a "lean against the wind" strategy. And, conversely, a monetary authority may not want to raise interest rates as an asset price bubble collapses. ${ }^{3}$

\section{Asset Price Inflation Block}

Overall asset price inflation equals the (implicitly weighted) sum of the fundamental component of asset price inflation and the bubble component of asset price inflation:

$$
\pi_{A P, t}=\pi_{F, t}+\pi_{B, t}
$$

Each component is described in the asset price inflation block of the model: ${ }^{4}$

\footnotetext{
${ }^{3}$ The IMF (1999) notes that the correlation between equity price inflation and consumer price inflation is negative contemporaneously as well as when equity price inflation is lagged. This may be partly explained by supply shocks. The explanation may also include investor psychology in low inflation environments.

${ }^{4}$ Modeling the role of asset prices — both the fundamental and bubble portion - is quite controversial for several reasons. First, as Cogley points out, identifying the bubble component of an asset price is nearly impossible to do econometrically. Hence, a full maximum likelihood estimation approach is unlikely to shed light on the role. Second, standard general equilibrium theory suggests that the fundamental component of asset prices does not play
} 


\section{Asset Price Inflation Block}

$$
\begin{aligned}
& \text { (F) } \pi_{F, t}=\pi_{t-1}+0.5 y_{t-1}+v_{t} \\
& \text { (B) } \pi_{B, t}=\zeta_{t}
\end{aligned}
$$

The fundamental component of asset price inflation is assumed to be a function of lagged inflation, output growth, and an error term that captures unexpected changes in the fundamental component of asset price inflation. ${ }^{5}$ The error term, $v_{t}$, is assumed to be distributed as a normal random variable with a zero mean and $\sigma_{v}^{2}(=5.3)$ variance.

The asset price bubble component is modeled as being exogenous. This specification is somewhat arbitrary because economists do not have good empirical models of asset price bubbles. The specification of the bubble is consistent, though, with some key features that economists generally attribute to a bubble. First, an asset price bubble causes asset prices to significantly deviate from their fundamental value. Second, the departures are serially correlated. Third, asset price bubbles can be positive or negative and collapse without warning. The following chart shows an example of this type of bubble.

an independent role in determining economic variables because they simply reflect economic fundamentals. If so, the macroeconomic model block would be misspecified. (An independent role of asset prices may depend on more fundamental issues of whether the economy is best characterized as an overlapping-generations model rather than an infinitely-lived agent model. Such an issue goes well beyond the scope of this paper.) Third, there is little justification for any particular stochastic process for the asset price bubble. All three issues are critical and may limit the applicability of the lessons drawn in the paper.

${ }^{5}$ Rather than a formal asset price formula, this equation can be thought of as a reduced-form econometric equation of the fundamental component of real asset prices. Standard asset pricing equations based on the present discounted value of future dividends might suggest that the interest rate should belong in the equation. This channel is ignored for simplicity and for pragmatic reasons. First, asset prices tend to exhibit random walk-type behavior and interest rates are not particularly good predictors of future asset price changes. Second, this specification would be broadly consistent with the present value model of asset prices if the short-run deviation of the interest rate around its steady state value has only a small impact on the subjective discount rate of future earnings. 


\section{Figure 1}

Example of the Path of an Asset Price Bubble

Level of Nonfundamental Asset Price

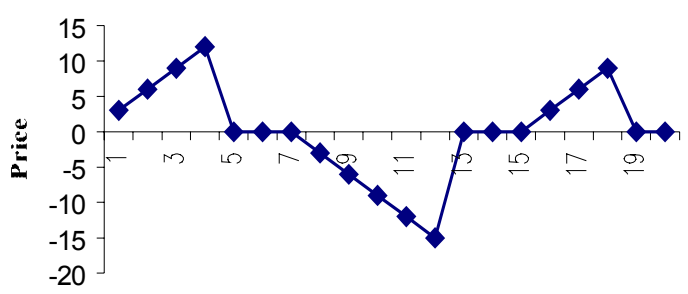

Time periods
Bubble Growth Rate

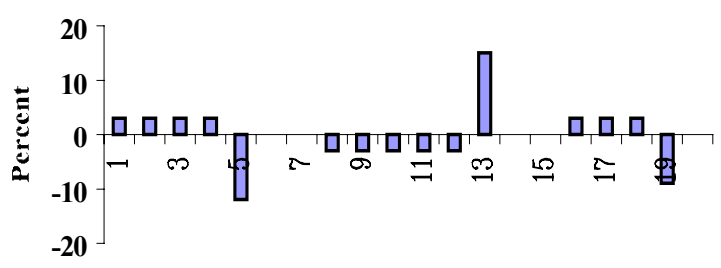

Time periods

Technically, the bubble evolves according to a 3-state stochastic process where -1 represents a negative bubble, 0 represents a no-bubble state, and 1 represents a positive bubble:

$$
I_{t}=\left\{\begin{array}{c}
1,+ \text { bubble } \\
0, \text { no bubble } \\
-1, \text { - bubble }
\end{array}\right.
$$

with Markovian probabilities governing the transitions:

$$
P\left(I_{t} \mid I_{t-1}\right)=\left(\begin{array}{ccc}
p_{-1,-1} & p_{-1,0} & 0 \\
p_{0,-1} & p_{0,0} & p_{0,1} \\
0 & p_{1,0} & p_{1,1}
\end{array}\right)
$$

The growth rate of the asset price bubble can be described in terms of a multinomial probability distribution 


$$
\pi_{B, t}=\zeta_{t}=\left\{\begin{array}{cc}
\theta_{u} & \text { with probability } p_{1,1}, \text { given }_{t-1}=1 \\
-\theta_{u} \tau & \text { with probability } 1-p_{1,0}, \text { given } s_{t-1}=1 \\
\theta_{u} & \text { with probability } 1-p_{0,1}, \text { given } s_{t-1}=0 \\
0 & \text { with probability } 1-p_{0,0}, \text { given } s_{t-1}=0 \\
\theta_{d} & \text { with probability } 1-p_{0,-1}, \text { given } s_{t-1}=0 \\
\theta_{d} & \text { with probability } 1-p_{-1,-1}, \text { given } s_{t-1}=-1 \\
-\theta_{d} \tau & \text { with probability } 1-p_{-1,0}, \text { given } s_{t-1}=-1
\end{array}\right.
$$

where $\tau$ tracks the duration of the bubble phase. Technically, $\tau$ measures the partial sum of the asset price bubble's duration. The asset price bubble in the simulations is parameterized as follows: $\theta_{u}=0.40, \theta_{d}=0.45, p_{1,1}=0.9, p_{0,0}=0.85, p_{0,1}=0.1$, and $p_{-1,-1}=0.8$.

Several properties of the bubble specification deserve attention. First, the bubble is assumed to evolve independently of the other variables in the economy. As a result, nothing in particular initiates a bubble and nothing in particular bursts a bubble. This feature has important implications for monetary policy because it rules out incentives for the monetary authority to "prick the bubble." Second, the growth rate of the positive bubble need not coincide with the growth rate of the negative bubble. Third, the collapse of the bubble is assumed to be immediate and complete. Fourth, the restriction that $p_{-1,1}=0$ and $p_{1,-1}=0$ precludes the economy from transiting from a positive bubble to a negative bubble without visiting the no-bubble state. Fifth, the probabilities of the Markovian process imply that the expected conditional duration of a bubble is equal to the expected unconditional duration of a bubble. For example, in the case of a positive bubble, the expected duration (in periods such as quarters) is simply $1 / p_{1,1}$. Finally, while $I_{t}$ follows a 3-state Markov process, the specification of $\zeta_{t}$ is a semi-Markov process 
because of the dependence on $\tau$. The duration variable, $\tau$, is used to track the deviation of an asset price from its fundamental value in order to guarantee the asset price returns to its fundamental value after the collapse of a bubble.

\section{Monetary Policy Block}

The monetary authority sets monetary policy by adjusting the short-term real interest rate. $^{6}$ It is assumed that the monetary authority chooses the real interest, $r$, in order to minimize its quadratic loss preference function

\section{Monetary Authority's Preferences \\ $L=\operatorname{var}(y)+\mu_{\pi} \operatorname{var}(\pi)+\mu_{r} \operatorname{var}\left(r-r_{-1}\right)$}

subject to constraints implied by the macroeconomic model described above. In this

environment, the optimal monetary policy is just a linear function of the variables that describe the state of the economy:

\section{Optimal Monetary Policy Rule}

$$
r_{t}=a_{y} y_{t}+a_{\pi} \pi_{t}+a_{F} \pi_{F, t}+a_{B} \pi_{B, t}
$$

In this model, optimal monetary policy is a choice of $\left\{a_{y}, a_{\pi}, a_{F}, a_{B}\right\}$ that minimizes the loss function, $L$.

As a means of comparison, two alternative monetary policy rules are evaluated. The first alternative corresponds to a the monetary authority that does not respond to asset price inflation:

\section{Alternative Policy Rule 1}

$$
r_{t}=a_{y} y_{t}+a_{\pi} \pi_{t}
$$

This rule is consistent with conventional Taylor-type rules.

\footnotetext{
${ }^{6}$ In practice, central banks use nominal interest rates as their policy tool. Given the inflation rate, the central bank is essentially choosing a real rate when it picks its nominal interest rate. Also, see Woodford (2001) for the types of assumptions that would justify using a short-term real interest rate as a sufficient statistic to link monetary policy to the macroeconomic environment via the $I S$ curve.
} 
The second alternative corresponds to a monetary authority that responds to overall asset price inflation, $\pi_{A P, t}$ :

\section{Alternative Policy Rule 2 \\ $r_{t}=a_{y} y_{t}+a_{\pi} \pi_{t}+a_{A P} \pi_{A P, t}$}

It is assumed that the monetary authority does not or cannot distinguish overall asset price inflation from its component parts.

\section{RESULTS AND INTERPRETATIONS}

I use this framework to analyze four questions:

- Is it optimal for a monetary authority to respond to the fundamental component of asset prices and asset price bubbles?

- If the monetary authority can't identify the bubble component of overall asset price movements, is it useful for the monetary authority to respond to overall asset prices?

- How do the benefits of responding to asset prices and asset price bubbles change as the monetary authority's preference to smooth interest rates strengthens?

- How does uncertainty about the role of asset prices in the economy affect the optimality of responding to asset prices?

Question 1: Is it optimal for a monetary authority to respond to the fundamental component of asset prices and asset price bubbles?

Figure 2 shows that the monetary authority can improve economic outcomes by responding to asset prices. The location of the policy frontier for the optimal policy rule (that includes responses to the components of asset prices) uniformly achieves a lower variance of output and inflation than a policy rule that does not respond to asset prices. Table 1 confirms 
this finding. In this table, the response coefficients for the fundamental component of asset price inflation and for the bubble component of asset price inflation (given different values of $\mu_{\pi}$ ) are typically large and positive. In fact, the response coefficients for the bubble component are quite close to the coefficients for the fundamental component when $\mu_{\pi}$ is low, i.e. when the monetary authority takes a relatively dovish attitude toward inflation stabilization. ${ }^{7}$

The positive values of the response coefficients imply the monetary authority (following an optimal rule) should raise the interest rate in order to offset the effects of asset price inflation on inflation and output. The size of the coefficients also suggests that when $\mu_{\pi}$ is low, the monetary authority should respond aggressively to asset price bubbles to control output variation. However, when $\mu_{\pi}$ is high, asset price bubbles help to smooth inflation variability because of the role of the nominal asset price bubble inflation in the $P C$ equation. In fact, the negative response coefficients suggest that it may be optimal for the monetary authority to ease monetary policy when the bubble is positive and tighten policy when the bubble is negative.

Overall, these results confirm the general intuition from linear-quadratic optimal control problems. If any economic variable provides information--however noisy--about the state of the economy, the decision-maker will generally benefit from using the information. Since asset prices enter into the model of the macroeconomy in a nontrivial way, it is not surprising that the asset prices show up with fairly large optimal response coefficients in the monetary authority's policy rule. The lesson learned is that informative economic variables should be included in the optimal monetary policy reaction function.

\footnotetext{
${ }^{7}$ Bernanke and Gertler (2001) claim that randomizing over possible realizations of the asset price bubble might eliminate the attractiveness of responding to asset prices. Also see Batini and Nelson. Figure 2 shows that the monetary authority finds responding to asset prices quite attractive, despite the fact that the asset price bubble specification is stochastic (as described in section II).
} 
Figure 2

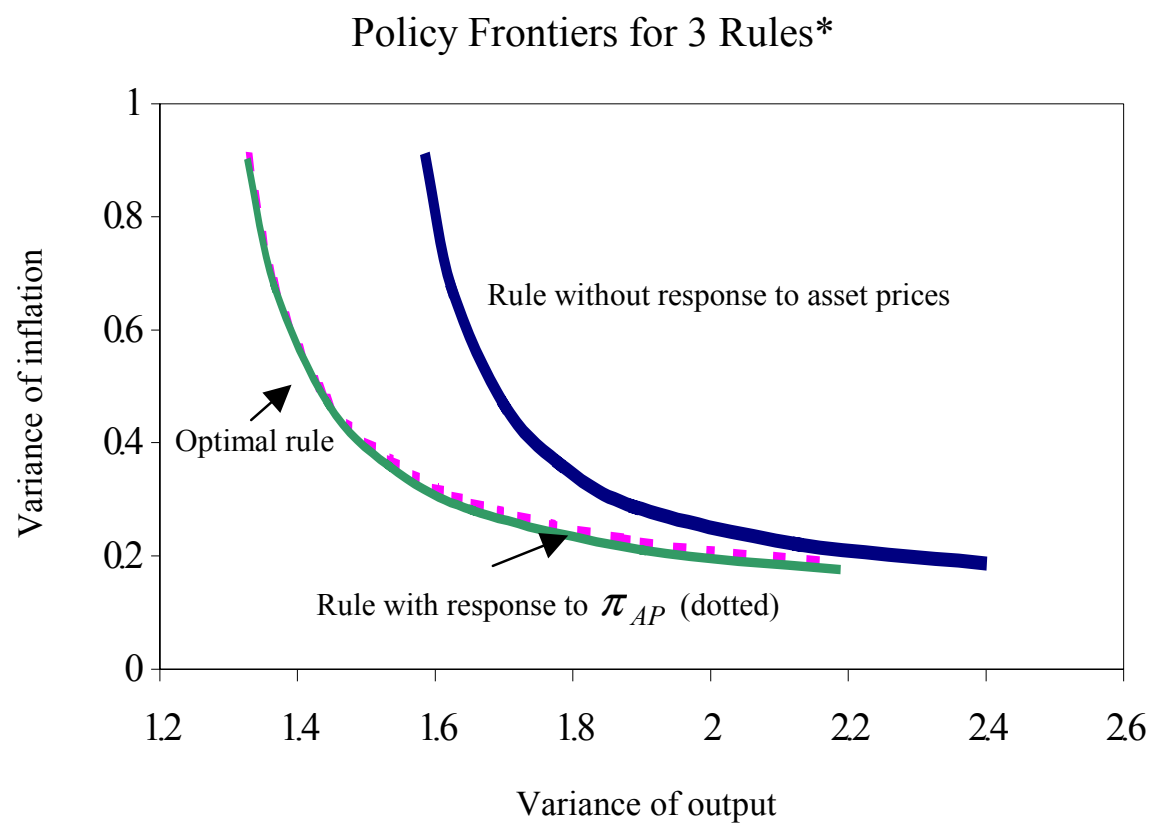

Notes

- Assumes that $\mu_{r}=0$, that is, the monetary authority puts no weight on the variance in the change in interest rates.

- "Rule without response to asset prices" is $r_{t}=a_{y} y+a_{\pi} \pi$

- "Rule with response to $\pi_{A P}$ " is $r_{t}=a_{y} y+a_{\pi} \pi+a_{A P} \pi_{A P}$

- "Optimal rule" is $r_{t}=a_{y} y+a_{\pi} \pi+a_{F} \pi_{F}+a_{B} \pi_{B}$

Table 1

\begin{tabular}{ccccc}
\hline$\mu_{\pi}$ & $a_{y}^{*}$ & $a_{\pi}^{*}$ & $a_{F}^{*}$ & $a_{B}^{*}$ \\
\hline $1 / 10$ & 3.2 & .3 & 1.0 & .9 \\
$1 / 5$ & 3.3 & .9 & 1.0 & .8 \\
$1 / 2$ & 3.5 & 2.0 & 1.0 & .7 \\
1 & 3.7 & 3.3 & 1.0 & .6 \\
2 & 4.0 & 5.0 & 1.0 & .5 \\
5 & 4.4 & 8.1 & 1.0 & .1 \\
10 & 4.9 & 11.2 & 1.0 & -.2 \\
\hline
\end{tabular}


Question 2: If the monetary authority can't identify the bubble component of overall asset price movements, is it useful for the monetary authority to respond to overall asset prices?

In the previous simulation exercise, it was assumed that the monetary authority can identify the bubble component of asset price movements. The ability to do so in practice is quite difficult. So, what is the implication if the monetary authority cannot identify the asset price bubble?

Figure 2 illustrates the consequences for the variance of inflation and output. The dotted line represents the policy frontier for a monetary authority that responds to overall asset price inflation instead of each component of asset price inflation. The close proximity of this curve with the optimal monetary policy rule curve indicates that the marginal benefits of responding to each component separately versus responding to the overall measure are small.

Table 2 reports the response coefficients for the policy rule. The response coefficients on output and inflation are nearly identical to those in Table 1, as might be expected given the position of the curves in Figure 2. When $\mu_{\pi}$ is low (i.e. the monetary authority is an inflation stabilization dove), the asset price response coefficient is roughly equal to the response coefficients for the fundamental component and the bubble component. As $\mu_{\pi}$ rises, the asset price bubble weighs more heavily on the mind of the monetary authority because of the bubbles direct effect on consumer price inflation via the $P C$ equation. Hence, it should not be a surprise that the value of $a_{A P}^{*}$ converges toward $a_{B}^{*}$.

The general lesson to learn here is that even if the monetary authority cannot perfectly measure the fundamental and bubble components separately, it still may be optimal to respond to overall asset prices. Being unable to separate the two components means that overall asset price 
inflation is a noisy, but somewhat informative measure of future output and inflation. In general, noisy measures of a variable belong in the optimal monetary policy reaction function. ${ }^{8}$

Table 2

\begin{tabular}{cccc}
\hline$\mu_{\pi}$ & $a_{y}^{*}$ & $a_{\pi}^{*}$ & $a_{F}^{*}$ \\
\hline $1 / 10$ & 3.2 & .4 & 1.0 \\
$1 / 5$ & 3.3 & .9 & 1.0 \\
$1 / 2$ & 3.5 & 2.1 & 0.9 \\
1 & 3.7 & 3.3 & 0.9 \\
2 & 3.9 & 5.0 & 0.9 \\
5 & 4.4 & 8.2 & 0.8 \\
10 & 4.8 & 11.2 & 0.7 \\
\hline
\end{tabular}

Question 3: How do the benefits of responding to asset prices and asset price bubbles change as the monetary authority's preference to smooth interest rates strengthens?

Recent research suggests that central banks, and in particular the Fed, prefer to smooth interest rate changes. ${ }^{9}$ In the model used in this paper, interest rate smoothing is a feature of the monetary authority's preferences. When $\mu_{r}$ is non-zero, the monetary authority behaves as if it cares about interest rate volatility. To explore the implication of such preferences, Figure 3 and Table 3 report the results from simulations with $\mu_{r}=1$.

Figure 3 shares important features with Figure 2. First, optimal monetary policy rules that respond to asset prices are better than monetary policy rules that ignore asset prices.

\footnotetext{
${ }^{8}$ This lesson is consistent with the results of Cecchetti et al. They find in their model little marginal benefit of being able to identify the asset price bubble. So, in their model as in my model, a monetary authority can improve economic outcomes even if the monetary authority cannot identify the bubble component.

${ }^{9}$ Such an assumption is justified in several ways. First, central banks are often mandated to promote market stability. Second, Woodford (1999) points out that such behavior is an integral part of an optimal monetary policy. Third, Sack and Wieland shows this smoothing behavior is pervasive in the central banking world.
} 
Second, the marginal benefits of responding to the fundamental and bubble components separately are small. But, Figure 3 differs from Figure 2 in several important ways. First, when the monetary authority prefers to smooth interest rates, the variability of inflation and/or output rises. This reflects the fact that the real interest rate is the only lever to stabilize output and inflation. If the monetary authority puts subjective constraints on interest rate variability, then the monetary authority will generally produce higher variability in inflation, output growth or both. Second, the policy frontiers are not monotonically declining in the variance of output growth. Sliding down the policy frontier corresponds to the consequences of a monetary authority that is progressively more concerned about inflation stabilization ( $\mu_{\pi}$ rises). The reason both the variance of output and the variance of inflation can decline is that the costs of lowering both is smaller than the cost of allowing the interest volatility to rise.

What happens to the benefits of responding to asset prices when the monetary authority cares about the variability of interest rates? Table 3 shows that the response coefficients for the fundamental component of asset prices and the bubble component of asset prices fall to zero. Essentially, the cost of using volatile asset prices (interest rate volatility) offsets than the benefits of the information contained in asset prices to stabilize output and inflation. ${ }^{10}$ As a result, the two previous lessons are not useful in a world where the monetary authority is sufficiently averse to variable interest rates.

The lesson to be taken from these findings is that even though asset prices contain useful information about output and inflation, the cost in terms of interest rate volatility can be so high as to cause the monetary authority to largely disregard the information. ${ }^{11}$

\footnotetext{
${ }^{10}$ It is also interesting to note that the response coefficients in this table are closer to the response coefficients used in the original Taylor rule than those found in Table 1.

${ }^{11}$ This lesson is consistent with Bernanke and Gertler's conclusion that by responding to stock prices, a central bank could worsen economic outcomes. Bernanke and Gertler $(1999,2001)$ argue that the potential costs of responding
} 


\section{Figure 3}

Policy Frontiers with Central Bank Preference for Interest Rate Smoothing

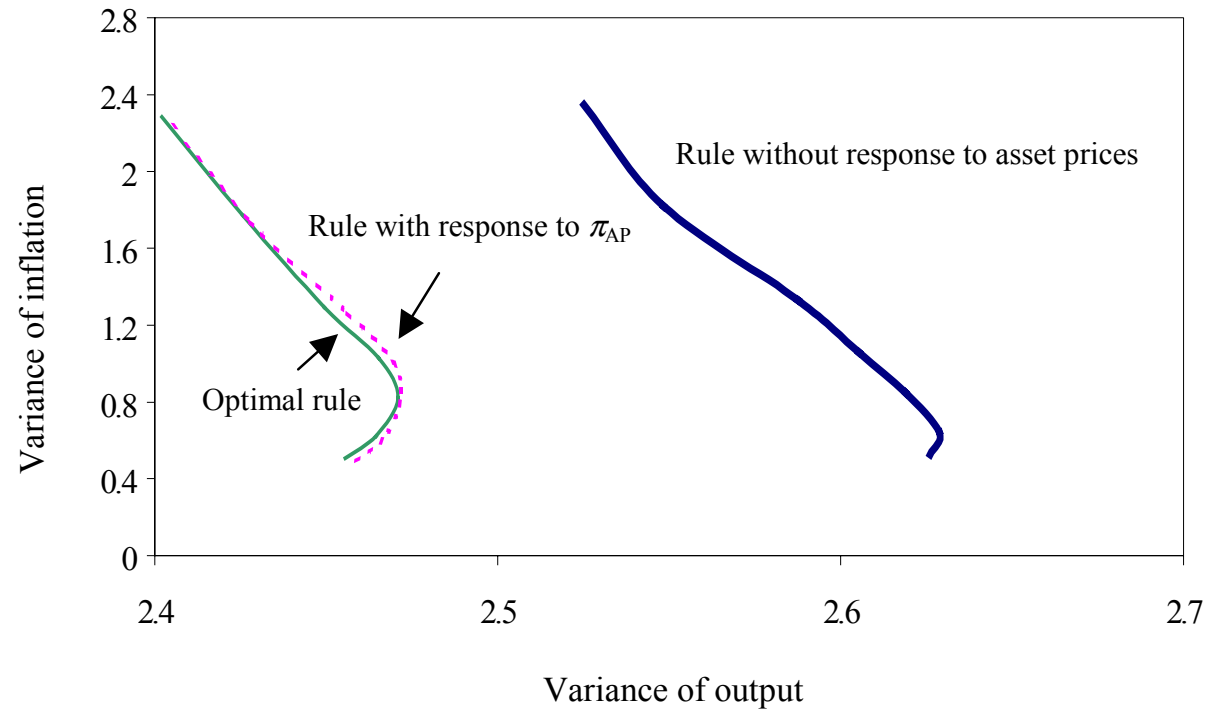

Notes

- Assumes that $\mu_{r}=1.0$, that is, the monetary authority puts weight on the variance in the change in interest rates.

- "Rule without response to asset prices" is $r_{t}=a_{y} y+a_{\pi} \pi$

- "Rule with response to $\pi_{A P}$ " is $r_{t}=a_{y} y+a_{\pi} \pi+a_{A P} \pi_{A P}$

- "Optimal rule" is $r_{t}=a_{y} y+a_{\pi} \pi+a_{F} \pi_{F}+a_{B} \pi_{B}$

Table 3

\begin{tabular}{ccccc}
\hline$\mu_{\pi}$ & $a_{y}^{*}$ & $a_{\pi}^{*}$ & $a_{F}^{*}$ & $a_{B}^{*}$ \\
\hline $1 / 10$ & 0.4 & 0.6 & 0.1 & 0.0 \\
$1 / 5$ & 0.4 & 0.9 & 0.1 & 0.0 \\
$1 / 2$ & 0.5 & 1.2 & 0.1 & 0.0 \\
1 & 0.5 & 1.6 & 0.1 & 0.0 \\
2 & 0.6 & 2.1 & 0.1 & 0.0 \\
5 & 0.8 & 2.9 & 0.1 & 0.0 \\
10 & 1.0 & 3.6 & 0.2 & -0.1 \\
\hline
\end{tabular}

to asset price can be quite large because asset prices can be too volatile relative to their information content. Vickers draws a similar conclusion. 
Question 4: How does uncertainty about the role of asset prices in the economy affect the optimality of responding to asset prices?

Uncertainty about the macroeconomic role of asset prices can affect the attractiveness of responding to asset prices. It is quite possible that the benchmark model in this paper is fundamentally misspecified. In fact, a well-specified macroeconomic model may not have an independent role for asset prices because they simply may reflect other economic fundamentals. If asset prices only reflect other fundamentals, then they would not show up in the state vector, and hence would not show up in the optimal monetary policy reaction function. The monetary authority would have to take this type of uncertainty into account when deciding to respond to asset prices.

To get at the heart of this issue, I model the monetary authority as facing a simple type of uncertainty about the macroeconomic role of asset prices. Either asset prices are modeled correctly in the benchmark model or $\phi=0$ and $\beta=0 .{ }^{12}$ In this environment, the monetary authority needs to assess the losses and probabilities associated with the four possible outcomes: Either asset prices matter or they do not in the economy, and the monetary authority believes that either asset prices matter or they do not. For each possible outcome, the loss function of the monetary authority can be evaluated as in Table 4 .

If the probabilities of each outcome are known, then the expected net benefits can be calculated. Rather than estimating the probabilities, I tabulate the probabilities. In this approach, a monetary authority that has a subjective probability about the relevance of asset prices could

\footnotetext{
${ }^{12}$ This approach is similar to that in Filardo (2000)
} 


\section{Table 4}

$\underline{\text { True macroeconomic structure }}$

\section{Monetary \\ authority's view}

Monetary authority's view
Asset prices matter

Asset prices do not matter

Asset prices matter

Asset prices do not matter

\begin{tabular}{|c|c|}
\hline \multicolumn{1}{|c|}{ Asset prices matter } & $\begin{array}{c}\text { Asset prices do } \\
\text { not matter }\end{array}$ \\
\hline $\mathrm{L}_{1,1}=1.93$ & $\mathrm{~L}_{1,2}=2.28$ \\
\hline $\mathrm{L}_{2,1}=2.16$ & $\mathrm{~L}_{2,2}=1.93$ \\
\hline
\end{tabular}

Probability structure

Asset prices matter Asset prices do not matter

\begin{tabular}{|l|l|}
\hline $\mathbf{P}_{\text {matter }}$ & $\mathbf{1 - \mathbf { P } _ { \text { matter } }}$ \\
\hline $\mathbf{P}_{\text {matter }}$ & $1-\mathbf{P}_{\text {matter }}$ \\
\hline
\end{tabular}

check this type of table to see whether it should respond to asset prices. ${ }^{13}$ To simplify the problem further, I assume that the probabilities are modeled as being independent of the actions of the monetary authority. This allows the expected net benefits to be calculated conditional on the subjective probability of the monetary authority.

The net benefit of responding to asset prices is defined as the expected change in the loss function (in terms of economic volatility) when asset prices "truly" matter relative to the

\footnotetext{
${ }^{13}$ I assume that the monetary authority has a subjective probability over the various outcomes. While I am agnostic about where such estimates come from, it is not unreasonable to believe that the monetary authority does have such an estimate. For example, policymakers make statements that suggest that they can identify bubbles and assess the consequence for the economy. I liken this view to a famous quotation from Justice Potter Stewart: "It has been said of that definition [of obscenity], 'I could never succeed in [defining it] intelligibly, but I know it when I see it."' (1964).
} 
expected change in the loss function when asset prices do not help to determine output and inflation. See the Technical Appendix for further details. Table 5 presents the expected net benefits of responding to asset prices in this economic environment for various probabilities. In this table, the key probability threshold is 60 percent. If the monetary authority is more than 60 percent sure that asset prices matter in the economy, then it would be optimal to respond to asset prices. However, if policymakers are less than 60 percent sure, then it is not optimal to respond to asset prices.

Table 5

\begin{tabular}{c|c|c|c|}
\hline $\begin{array}{c}\text { Probability that } \\
\text { asset prices matter }\end{array}$ & $\begin{array}{c}\text { Expected benefit if } \\
\text { CB responds to AP }\end{array}$ & \multicolumn{1}{c}{$\begin{array}{c}\text { Expected cost if } \\
\text { CB responds to AP }\end{array}$} & Net benefits \\
\hline 0 & 0.00 & 0.35 & -0.35 \\
\hline 10 & 0.02 & 0.32 & -0.29 \\
\hline 20 & 0.05 & 0.28 & -0.23 \\
\hline 30 & 0.07 & 0.25 & -0.18 \\
\hline 40 & 0.09 & 0.21 & -0.12 \\
\hline 50 & 0.12 & 0.18 & -0.06 \\
\hline 60 & 0.14 & 0.14 & 0.00 \\
\hline 70 & 0.16 & 0.11 & 0.06 \\
\hline 80 & 0.18 & 0.07 & 0.11 \\
\hline 90 & 0.21 & 0.04 & 0.17 \\
\hline 100 & 0.23 & 0.00 & 0.23 \\
\hline
\end{tabular}

This table illustrates that if a monetary authority is fairly confident about the structure of the economy, then responding to asset prices and asset price bubbles is generally optimal. The response is optimal because the monetary authority is sufficiently confident that the expected 
benefits of responding to asset prices - which contain valuable information about future output and inflation variability—is greater than the expected costs of being wrong. ${ }^{14}$

\section{CONCLUSIONS AND FUTURE RESEARCH}

The findings of this investigation shed some light on optimal monetary policy in an economy with asset price bubbles. First, if asset prices play a nontrivial role in determining output and inflation, then the monetary authority may want to respond to changes in asset prices generally and asset price bubbles specifically. This conclusion also holds when asset prices are quite volatile. Second, even if the monetary authority is fairly uncertain about how to identify the bubble component, overall asset price movements may still contain valuable information to which the monetary authority may want to respond. Third, the desirability of using asset price information depends critically on the monetary authority's preference for interest rate smoothing and the variability of asset prices. Although asset prices contain useful information about output and inflation, a monetary authority may prefer to disregard the information because responding to asset prices might cause quite volatile interest rates. Fourth, if the monetary authority is uncertain about the macroeconomic role of asset prices and asset price bubbles, then the expected costs (in terms of economic volatility) of responding to asset prices may exceed the expected benefits. Given the current difficulties in identifying asset price bubbles and in estimating the role of asset prices in the macroeconomy, it is hard to imagine how the expected benefits could exceed the expected costs.

\footnotetext{
${ }^{14}$ The monetary authority's loss of responding to asset prices when asset prices don't matter can be quite large. One key part of the loss is due to the direct contribution of asset price volatility to interest rate volatility. In contrast, if a monetary authority chooses not to respond to asset prices and asset price bubbles, asset price variability only indirectly affects interest rate volatility. For example, when the monetary authority does not know the structure of the model, output and inflation appear (to the monetary authority) to be less predictable. All else the same, when the monetary authority perceives a higher variance of output and inflation, they will tend to vary interest rates more in order to stabilize output and inflation. As a result, the monetary authority acts as if it is more hawkish about output
} 
Future research may help increase our understanding of asset price and monetary policy. For example, a key issue not addressed in this paper is whether the monetary authority should try to deflate asset price bubbles. Because the bubble process is specified as being exogenous, the model cannot shed any light on the issue. One might reasonably conjecture, however, that the same factors that make responding to asset prices attractive to the monetary authority would also make deflating asset price bubbles attractive. Moreover, the same factors that make responding to asset prices unattractive would also make deflating asset price bubbles unattractive. Building a more sophisticated model to address this issue is left for future research.

In addition, the issues of monetary policy and asset prices will not be fully understood until the role of financial market fragility is incorporated into the model. The heart of the policy debate is not simply about output and inflation variability. Policymakers also worry about preventing systemic risks due to the collapse of asset price bubbles and might want to design institutional structures that help mitigate the likelihood of such events. A more elaborate analysis of the uncertainties may help improve our understanding of the policy options. One potentially fruitful approach may be to build on the recent research into robust control theory of monetary policy.

At this point in time, however, the research into asset prices and monetary policy is still in its infancy. With renewed research interest, considerable progress on various fronts may be made in the years ahead. This paper provided some practical policy lessons by studying optimal monetary policy in the presence of asset price bubbles. While there was no definitive answer to the question of whether monetary policy should respond to asset prices, the paper laid out some

and inflation stabilization than would be justified if the monetary authority were well aware of the structure of the economy. 
conditions when it is advisable and conditions when it is not advisable. Future research will likely refine these conditions rather than overturn the basic thrust of the policy lessons. 


\section{TECHNICAL APPENDIX}

This appendix provides technical details behind the monetary policy model, the simulation-based solution methods, and the methods to evaluate the implications of parameter uncertainty.

Monetary Policy Model

\section{Small-Scale Macro Model}

(IS) $y_{t}=-y_{t-1}+\theta y_{t-1}+\phi\left(\pi_{A P, t-1}-\pi_{t-1}\right)+\varepsilon_{t}$

(A1)

(PC) $\pi_{t}=\pi_{t-1}+\alpha y_{t-1}+\beta \pi_{B, t-1}+\eta_{t}$

$$
\begin{aligned}
& \text { (F) } \pi_{F, t}=\pi_{t-1}+\lambda y_{t-1}+v_{t} \\
& \text { (B) } \pi_{B, t}=\zeta_{t}
\end{aligned}
$$

\section{Monetary Policy Decision Problem}

Minimize $L=\operatorname{var}(y)+\mu_{r} \operatorname{var}(\pi)+\mu_{\pi} \operatorname{var}\left(r-r_{-1}\right)$

subject to the economy modeled in (A1).

The optimal policy is of the functional form $r_{t}=a_{y} y_{t}+a_{\pi} \pi_{t}+a_{F} \pi_{F, t}+a_{B} \pi_{B, t}$. This policy rule can be substituted into (A1) and be rewritten in a state-space representation:

\section{State-Space Representation}

$$
X_{t}=A X_{t-1}+B E_{t}
$$

where

$$
X_{t}=\left(\begin{array}{c}
y_{t} \\
\pi_{t} \\
\pi_{F, t} \\
\pi_{B, t}
\end{array}\right) \quad A=\left[\begin{array}{cccc}
\theta-\gamma a_{y} & -\gamma a_{\pi}-\phi & -\gamma a_{F}+\phi & -\gamma a_{B}+\phi \\
\alpha & 1 & 0 & \beta \\
\lambda & 1 & 0 & 0 \\
0 & 0 & 0 & 0
\end{array}\right]
$$




$$
B=\left[\begin{array}{llll}
1 & 0 & 0 & 0 \\
0 & 1 & 0 & 0 \\
0 & 0 & 1 & 0 \\
0 & 0 & 0 & 1
\end{array}\right] \text { and } E_{t}=\left(\begin{array}{c}
\varepsilon_{t} \\
\eta_{t} \\
v_{t} \\
\zeta_{t}
\end{array}\right)
$$

The first three error terms $\left(\varepsilon_{t}, \eta_{t}, v_{t}\right)$ have independent normal distributions with a known variance:

$$
\begin{aligned}
\varepsilon_{t} & \sim N\left(0, \sigma_{\varepsilon}^{2}\right) \\
\eta_{t} & \sim N\left(0, \sigma_{\eta}^{2}\right) . \\
v_{t} & \sim N\left(0, \sigma_{v}^{2}\right)
\end{aligned}
$$

The final error term, $\zeta_{t}$, determines the asset price bubble, $\pi_{B, t-1}$ and follows the multinomial probability distribution described in the text.

\section{Simulation-Based Solution Method}

Simulations are used to solve for the coefficients of the monetary policy rule that minimizes the monetary authority's objective function, $L^{*}$, where

$$
\begin{gathered}
L^{*}=\underset{\left\{a_{y}, a_{\pi}, a_{F}, a_{B}\right\}}{\arg \min } L \\
L=\operatorname{var}(y)+\mu_{\pi} \operatorname{var}(\pi)+\mu_{r} \operatorname{var}\left(r-r_{-1}\right) \text { and } r_{t}=a_{y} y_{t}+a_{\pi} \pi_{t}+a_{F} \pi_{F, t}+a_{B} \pi_{B, t} .
\end{gathered}
$$

Simulation method:

1) For each draw of $\widetilde{\varepsilon}=\left\{\varepsilon_{t}, \eta_{t}, v_{t}, \zeta_{t}\right\}$, calculate $\left\{a_{y}^{*}, a_{\pi}^{*}, a_{F}^{*}, a_{B}^{*}\right\}$ that minimizes the loss function, $L$.

2) Integrate out the dependence of any particular path of $\widetilde{\varepsilon}$ by simulation methods. For example, the estimate the distribution function, $f\left(\hat{a}_{y}\right)$, is

$$
f\left(\hat{a}_{y}\right)=\int_{\widetilde{\varepsilon}} f\left(\hat{a}_{y} \mid \widetilde{\mathcal{E}}\right) d F(\widetilde{\varepsilon})
$$


3) Estimate the reaction function parameters, $\left\{a_{y}, a_{\pi}, a_{F}, a_{B}\right\}$, and a dispersion measure (such as the mean and standard deviation).

The estimates in the paper are based on 500 simulations of a 1000-period economy. Evaluating Parameter Uncertainty

A central bank generally prefers to respond to asset prices if there is no parameter uncertainty. The intuition behind this result is that a central bank should not ignore valuable information about the state of the economy. This result does not generally hold in the case when there is uncertainty about the underlying structure of the macroeconomic model. This note lays out a method to evaluate the net benefits to a monetary authority of responding to asset prices when there is uncertainty about the macroeconomic role of asset prices.

The particular type of uncertainty considered is the possibility that the coefficients on the asset price variables are zero (that is, $\phi=0, \beta=0$ ). The possibilities facing the monetary authority are described in the following table:

\section{Table A1}

True macroeconomic structure

\begin{tabular}{cc|c|c|}
\multicolumn{1}{c}{} & \multicolumn{2}{c}{ AP matter } & AP do not matter \\
\cline { 3 - 3 } Monetary & AP matter & $L_{1,1}^{*}$ & $L_{1,2}$ \\
\cline { 2 - 3 } authority's view & AP do not matter & $L_{2,1}$ & $L_{2,2}^{*}$ \\
\cline { 3 - 4 } & &
\end{tabular}

- $L_{1,1}^{*}$ is the loss function value when the monetary authority correctly assumes that asset prices do play a fundamental role in the macroeconomy. The optimal monetary policy reaction function achieves the minimum loss.

- $L_{1,2}$ is the loss function value when the monetary authority incorrectly assumes that asset prices do play a fundamental role in the macroeconomy. Given the 
misperception, the central bank uses the reaction function assuming asset prices do play a role.

- $L_{2,2}^{*}$ is the loss function value when the monetary authority correctly assumes that asset prices do not play a fundamental role in the macroeconomy. The optimal monetary reaction function achieves the minimum loss.

- $L_{2,1}$ is the loss function value when the monetary authority incorrectly assumes that asset prices do not play a fundamental role in the macroeconomy. Given the misperception, the central bank uses the reaction function assuming asset prices do not play a role.

In such a setting, the monetary authority would want to incorporate this uncertainty in their calculation of the expected net benefits of responding to asset prices. The expected net benefit of responding to asset prices can be evaluated as the expected benefit of responding relative to the expected cost of responding. The expected benefit of responding when asset prices matter can be algebraically written as $E(B)=E(B \mid$ given asset prices matter $) * P($ asset prices matter $)=\left(L_{2,1}-L_{1,1}^{*}\right) * \operatorname{Prob}(\varphi \neq 0, \beta \neq 0)$ The expected cost of responding when asset prices do not matter is

$$
\begin{aligned}
E(C) & =E(C \mid \text { given asset prices do not matter }) * P(\text { asset prices do not matter }) \\
& =\left(L_{1,2}-L_{2,2}^{*}\right) *(1-\operatorname{Prob}(\varphi \neq 0, \beta \neq 0))
\end{aligned}
$$

If the expected cost of responding to asset prices exceeds the expected benefit, then the central bank should not respond to asset prices. If the converse is true, then the central bank should respond to asset prices. 


\section{Making this Approach Operational}

In general, direct comparisons of different specifications of the macroeconomy (i.e. where $(\phi=0, \beta=0)$ versus $(\phi \neq 0, \beta \neq 0))$ are not possible because of the different variancecovariance structure of the economy. One way to get at the cost of parameter uncertainty is to calibrate the different models so that the optimal monetary policy reaction function generates the same value of the loss function in each economic environment. This calibration exercise does not affect the optimal policy reaction function because linear-quadratic optimal control problems have a certainty-equivalence property. In other words, the optimal policy is independent of the error variances. ${ }^{15}$ Hence, error variances can be chosen to make $L_{2,2}^{*}=L_{1,1}^{*}$; in the paper $L_{1,1}^{*}$ was estimated to be 1.93. Graphically, the error variances can be chosen to move the curve labeled $\mathrm{f}\left(\phi=0, \beta=0, L_{1,1}^{*}=1.93\right)$. Then, the cost-benefit analysis described above can be done as a local approximation around the common intersection.

\section{Figure A1}

\section{Illustration of Calibration Exercise}

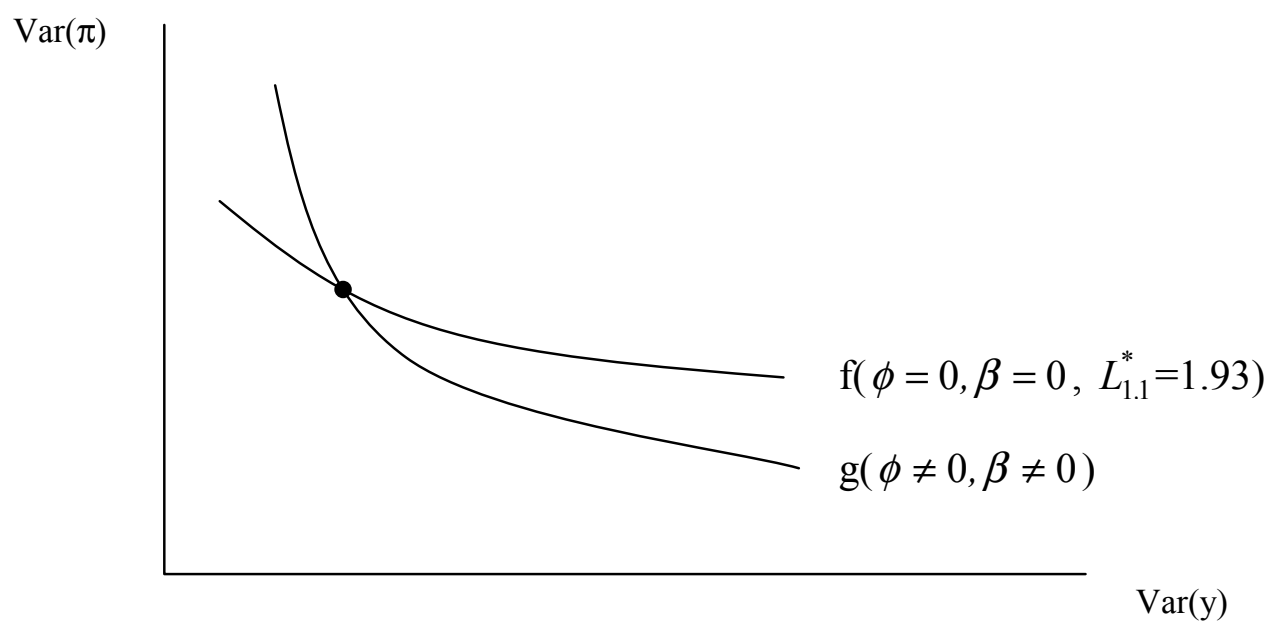

\footnotetext{
${ }^{15}$ Note that the optimal policy is unaffected by arbitrary affine transformations of the loss function, but the value of the loss function is not.
} 
With this information, the expected loss of responding to asset prices can be calculated quite easily using Bayes’ rule

$$
\mathrm{E}(\mathrm{L})=\frac{\sum P(A \mid B) P(B) L(A, B)}{\sum P(A, B)}
$$

where $\mathrm{P}(\mathrm{A} \mid \mathrm{B})$ is the subjective probability of the monetary authority that asset prices matter, given the true state of the world; $\mathrm{P}(\mathrm{B})$ is the probability that asset prices truly matter in the macroeconomy, and $\mathrm{L}(\mathrm{A}, \mathrm{B})$ is the state-contingent loss function. 


\section{REFERENCES}

Batini, Nicoletta, and Edward Nelson. 2000. "When the Bubble Bursts: Monetary Policy Rules and Foreign Exchange Market Behavior," Bank of England Working Paper.

Bernanke, Benjamin S. and Michael Woodford. 1997. "Inflation Forecasts and Monetary Policy," Journal of Money, Credit, and Banking, November.

Blanchard, Olivier, and Mark Watson. 1982. "Bubbles, Rational Expectations, and Financial Markets," in P. Wachtel, ed., Crisis in the Economic and Financial Structure, Lexington MA: Lexington Books.

Borio, C.E.V., N. Kennedy, and S.D. Prowse. 1994. "Exploring Aggregate Asset Price Fluctuations Across Countries: Measurement, Determinants and Monetary Policy Implications," BIS economic papers, no. 40, April.

Brainard, William. 1967. "Uncertainty and the Effectiveness of Policy," American Economic Review, May.

Capel, Jeannette, and Aerdt Houben. 1998. "Asset Inflation in the Netherlands: Assessment, Economic Risks and Monetary Policy Implications," in The Role of Asset Prices in the Formulation of Monetary Policy. Basle: Bank for International Settlements.

Cecchetti, Stephen G., Hans Genberg, John Lipsky, and Sushil Wadhwani. 2000. Asset Prices and Central Bank Policy. International Center for Monetary and Banking Studies: London.

Cogley, Timothy. 1999. "Should the Fed Take Deliberate Steps to Deflate Asset Price Bubbles," Federal Reserve Bank of San Francisco Economic Review.

Davis, Morris A., and Michael G. Palumbo. 2001. "A Primer on the Economics and Time Series Econometrics of Wealth Effects," Federal Reserve Board FEDS working paper, January.

Filardo, Andrew J. 2000. “Asset Prices and Monetary Policy,” Federal Reserve Bank of Kansas City Economic Review, $3^{\text {rd }}$ Quarter.

Gertler, Mark. 1998. "Asset Prices and Monetary Policy," in Bank for International Settlements, Asset Prices and Monetary Policy: Four Views. Basle: BIS.

Gertler, Mark, and Ben Bernanke. 1999. "Monetary Policy and Asset Price Volatility," in New Challenges for Monetary Policy, Kansas City: Federal Reserve Bank of Kansas City.

. 2001. "Should Central Banks Respond to Movements in Asset Prices?" American Economic Review, May.

Goodhart, Charles A. 1999. "Time, Inflation, and Asset Prices," Unpublished working paper, September. 
Goodhart, Charles A., and Boris Hofmann. 2000A. "Asset Prices and the Conduct of Monetary Policy," Unpublished London School of Economics working paper.

Goodhart, Charles A., and Boris Hofmann. 2000B. "Do Asset Prices Help to Predict Consumer Price Inflation?” Manchester School Journal, September.

International Monetary Fund. 1999. "Safeguarding Macroeconomic Stability at Low Inflation," World Economic Outlook, October.

Okina, Kunio, Masaaki Shirakawa, and Shigenori Shiratsuka. 2000. "The Asset Price Bubble and Monetary Policy: Japan's Experience in the Late 1980s and the Lessons," Bank of Japan, Institute For Monetary and Economic Studies Discussion Paper, May.

Poterba, James M. 2000. "Stock Market Wealth and Consumption," The Journal of Economic Perspectives, Spring.

Rudebusch, Glenn D., and Lars E. O. Svensson. 1999. "Policy Rules for Inflation Targeting," in John B. Taylor, ed., Monetary Policy Rules. Chicago: The University of Chicago Press.

Sack, Brian, and Volker Wieland. 1999. "Interest-rate Smoothing and Optimal Monetary Policy: A Review of Recent Empirical Evidence," Federal Reserve Board FEDS working paper, August.

Schinasi, Garry J. 1994. "Asset Prices, Monetary Policy, and the Business Cycle,” IMF Paper on Policy Analysis and Assessment, March.

Shiller, Robert J. 2000. Irrational Exuberance. Princeton: Princeton University Press.

Taylor, John B. 1999. "Introduction," in John B. Taylor, ed., Monetary Policy Rules. Chicago: The University of Chicago Press.

Taylor, John B. 1994. “The Inflation/Output Variability Trade-off Revisited," in Goals, Guidelines and Constraints Facing Monetary Policymakers. Boston: Federal Reserve Bank of Boston.

Vickers, John. 1999. “Monetary Policy and Asset Prices,” Bank of England Quarterly Bulletin, November.

West, Kenneth D. 1987. “A Specification Test for Speculative Bubbles,” Quarterly Journal of Economics, August.

Woodford, Michael. 2001. "Neo-Wicksellian Framework for the Analysis of Monetary Policy," Princeton University Working Paper.

. 1999. "Optimal Monetary Policy Inertia," Manchester School Supplement.

Wu, Yangru. 1997. "Rational Bubbles in the Stock Market: Accounting For the U.S. Stock Price Volatility," Economic Inquiry, April. 
Yamaguchi, Yutaka. 1999. "Asset Price and Monetary Policy," in New Challenges For Monetary Policy, Kansas City: Federal Reserve Bank of Kansas City. 